\title{
Magnetic texturing of bulk samples of the superconductor $\mathrm{Bi}_{2} \mathrm{Sr}_{2} \mathrm{Ca}_{0.8} \mathrm{Dy}_{0.2} \mathrm{Cu}_{2} \mathrm{O}_{8-y}$
}

\author{
S. Stassen ${ }^{\text {al }}$ and A. Rulmont \\ S.U.P.R.A.S., Chemistry Institute B6, University of Liège, Sart-Tilman, B-4000 Liège, Belgium \\ Ph. Vanderbemden and A. Vanderschueren \\ S.U.P.R.A.S., Montefiore Electricity Institute B28, University of Liège, Sart-Tulman, B-4000 Liège, Belgium \\ Z. Gabelica \\ Facultés Universitaires de Namur, Département de Chimie. Laboratoire de Catalyse, 61 rue de Bruxelles, \\ B-5000 Namur. Belgium \\ R. Cloots ${ }^{\text {b) }}$ \\ S.U.P.R.A.S., Chemistry Institute B6, University of Liège, Sart-Tilman, B-4000 Liège, Belgium \\ M. Ausloos ${ }^{\text {c) }}$ \\ S.U.P.R.A.S, Physics Institute B5, University of Liège, Sart-Tilman, B-4000 Liège, Belgium
}

(Received 9 November 1994; accepted for publication 31 August 1995)

The texturing process of $\mathrm{Bi}-\mathrm{Sr}-\mathrm{Ca}(\mathrm{Dy})-\mathrm{Cu}-\mathrm{O}(2212)$ is optimized by sintering under a magnetic field. The precursor crystalline powder is melted and grown under a $1.2 \mathrm{~T}$ magnetic field. Textured samples are characterized by $\mathrm{x}$-ray diffraction, scanning electron microscopy, electrical resistivity, and magnetic susceptibility. (C) 1996 American Institute of Physics. [S0021-8979(96)00601-9]

Weak links in bulk polycrystalline superconductors can be attributed to high-angle grain boundaries, intergranular impurities, or secondary phases. microcracks induced during thermal cycling, and porosity. Grain alignment is thus one of the necessary key ingredients to eliminate weak links in superconducting ceramics. Several techniques have been proposed in order to texture such ceramic materials, especially for YBCO compounds. ${ }^{1,2}$ For Bi-based superconductors, only a partial melting ${ }^{3-5}$ and a mechanical process at high temperature ${ }^{6-10}$ have been successfully used in order to texture the materials.

In our group, we are interested in using a magnetic field to texrure $\mathrm{YBCO}^{2,11}$ and $\mathrm{Bi}$-based materials. The purpose of the present study is to demonstrate that the melting growth process under a magnetic field can produce highly textured Bi-2212 bulk ceramics. Alignment results from the anisotropic paramagnetic susceptibility of the grains. ${ }^{12}$ The magnetic anisotropy is further enhanced by substituting a strongly anisotropic rare-earth ion like dysprosium for calcium. ${ }^{13}$ It was shown that $20 \%$ Dy substitution on the Ca sites does not deteriorate the superconducting properties. ${ }^{14}$ In previous work, we tried to texture a glassy $\mathrm{Bi}_{2} \mathrm{Sr}_{2} \mathrm{Ca}_{0.8} \mathrm{Dy}_{0.2} \mathrm{Cu}_{2} \mathrm{O}_{8-y}$ material during recrystallization under a $0.6 \mathrm{~T}$ magnetic field. ${ }^{15}$ That experiment showed that texturing only occurred in the partially molten part of the sample. We have thus optimized this magnetic field process in order to texture the bulk of the sample. This time, the precursor is a crystalline $\mathrm{Bi}_{2} \mathrm{Sr}_{2} \mathrm{Ca}_{0.8} \mathrm{Dy}_{0.2} \mathrm{Cu}_{2} \mathrm{O}_{8-y}$ powder

\footnotetext{
"Author to whom correspondence should be addressed.

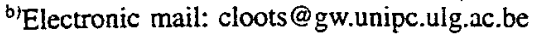

'Electronic mail: ausloos@gw.unipc.ulg.ac.be
}

which is melted at the most favorable temperature and then cocled down for crystal growth under a $1.2 \mathrm{~T}$ magnetic field. Results show a particularly well-textured 2212 material with strong anisotropic properties.

The synthesis of $\mathrm{Bi}_{2} \mathrm{Sr}_{2} \mathrm{Ca}_{0.8} \mathrm{Dy}_{0.2} \mathrm{Cu}_{2} \mathrm{O}_{8-y}$ starts from a mixture of stoichiometric amounts of $\mathrm{Bi}_{2} \mathrm{O}_{3}, \mathrm{SrCO}_{3}, \mathrm{CaCO}_{3}$, $\mathrm{Dy}_{2} \mathrm{O}_{3}$, and $\mathrm{CuCO}_{3} . \mathrm{Cu}(\mathrm{OH})_{2}$ treated at $820^{\circ} \mathrm{C}$ for $48 \mathrm{~h}$, including two intermediate grindings. The crystalline powder, contained in an alumina crucible, is then introduced into a vertical furnace to be melted in air at normal pressure under a horizontal 1.2 T magnetic field. The best results are for a thermal cycle which reached $950^{\circ} \mathrm{C}$, a temperature above the melting point of our system, with a heating rate of $150^{\circ} \mathrm{C} / \mathrm{h}$. The cooling down part of the run drops to $800^{\circ} \mathrm{C}$ with a $2{ }^{\circ} \mathrm{C} / \mathrm{h}$ rate and is followed by a $50^{\circ} \mathrm{C} / \mathrm{h}$ decrease to room temperature. A zero field run under the same experimental conditions was always made as a control procedure.

The synthesized ceramics were removed from the alumina crucible to be analyzed. X-ray diffraction data were collected using $\mathrm{Cu} K_{\alpha}$ monochromatized radiation $(\lambda=1.5406$ $\AA$ ) with a Siemens D5000 diffractometer for the textured sample, for the zero-field specimen, and for the starting powder. The $\mathrm{x}$-ray diffraction pattern was recorded for the cross section perpendicular to the applied magnetic field. We believe that the bulk of the sample is probed since the sample has been cut in order to analyze a plane perpendicular to the applied magnetic field. The observed results are thus representative of the whole material and not due to surface effects. In 2212 substituted with a specific rare-earth element such as $\mathrm{Gd}$, Ho, or Dy, for which the field is supposed to orient the $c$-axis of the grains horizontally, only the $00 l$ reflections should be dominant in the $\mathrm{x}$-ray pattern and the other $h k l$ 

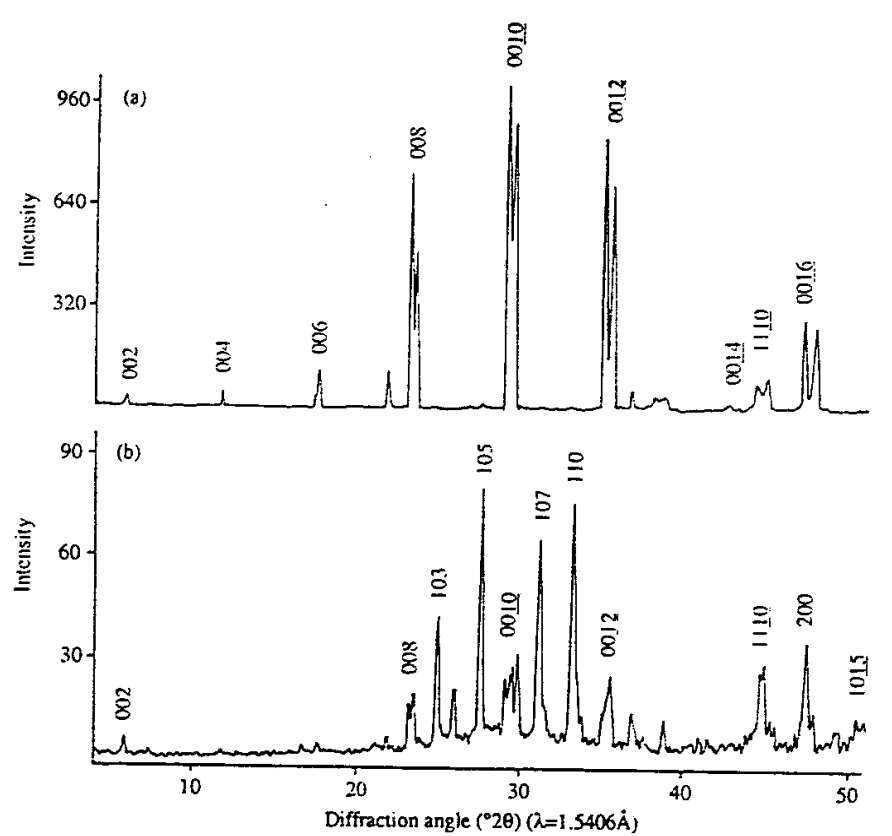

FIG. 1. X-ray diffraction patterns of $\mathrm{Bi}_{2} \mathrm{Sr}_{2} \mathrm{Ca}_{4.8} \mathrm{Dy}_{0.2} \mathrm{Cu}_{2} \mathrm{O}_{8-}$, samples (a) Textured in $1.2 \mathrm{~T}$-the observation plane is perpendicular to the applied magnetic field. (b) Zero-field specimen treated in the same experimental conditions.

peaks should be significantly diminished if texturing has taken place. ${ }^{13}$ As it is observed in Fig. 1(a), texturing has been achieved in the samples sintered under $1.2 \mathrm{~T}$ magnetic field since the $00 l$ reflection peaks are very much enhanced and are almost the only ones visible in the diffraction pattern. The intensity of the peaks is also very high when compared to the zero-fieid run specimen [Fig. 1(b)]. Indeed, for a sample sintered in the same experimental conditions, but without application of an external magnetic field, the $x$-ray pattern is totally different [Fig. l(b)]. Its profile looks like that of the crystalline powder obtained after the first synthesis stage. This means that obviously, no texture took place in the absence of an external magnetic field. Diffraction pattems of the samples indicate rather pure 2212 phase since (only) very small impurity peaks can be detected by $x$-ray diffractometry. The splitting of the $00 l$ peaks has been discussed in one of our previous articles. ${ }^{16}$

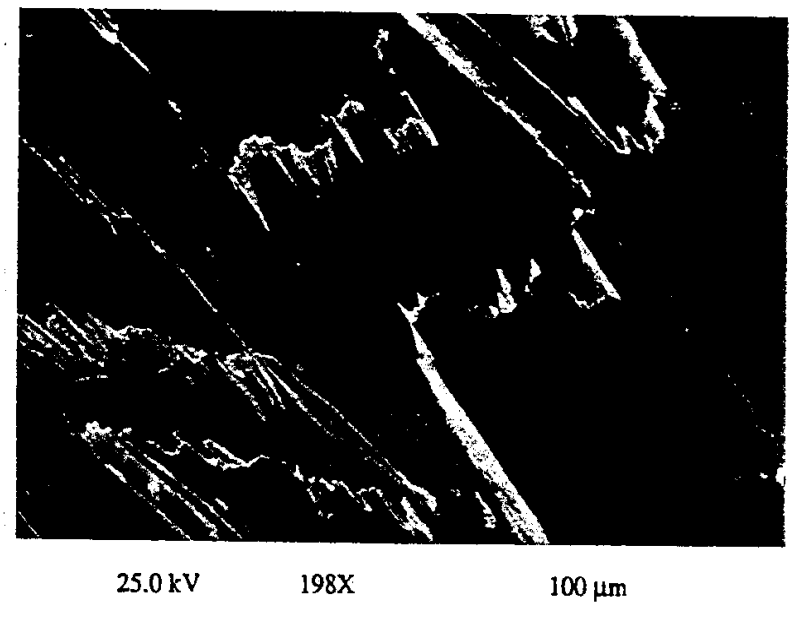

FIG. 2. SEM picture of a $\mathrm{Bi}_{2} \mathrm{Sr}_{2} \mathrm{Ca}_{0.8} \mathrm{Dy}_{0.2} \mathrm{Cu}_{2} \mathrm{O}_{8-y}$ sample prepared in a $1.2 \mathrm{~T}$ magnetic field.

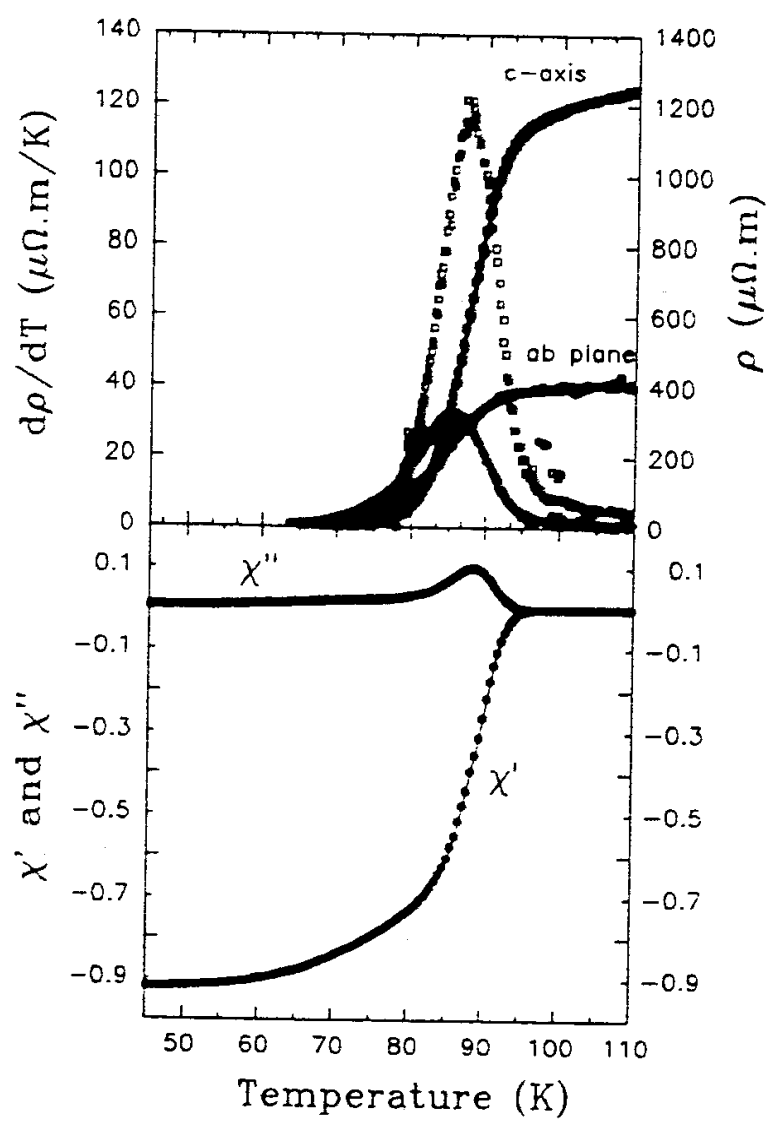

FIG. 3. (a) Electrical resistivity $\rho$ and its temperature derivative $d \rho / d T$ v: temperature for $\mathrm{Bi}_{2} \mathrm{Sr}_{2} \mathrm{Ca}_{4,8} \mathrm{Dy}_{0_{0}} \mathrm{Cu}_{2} \mathrm{O}_{k-1}$, sample textured in $1.2 \mathrm{~T}$ magnetic field. in which the current is applied parallel $(\mathbb{Q}$ and $\square$ for $\rho$ and $d \rho / d T$. respectively') or perpendicular ( $C$ and $C$ for $\rho$ and $d \rho / d T$. respectively) to the magnetic field direction and (b) ac magnetic susceptibility as a function of temperature measurement:

Par of the textured sample was later embedded in epoxy resin, cleaned with $\mathrm{SiC}$ paper, and polished with diamond paste before observation. Microstructural analysis has been performed with a Philips XL20 scanning electron microscope (SEM) with a $25 \mathrm{kV}$ accelerating voltage. The SEM picture (Fig. 2) of the sample sintered under a $1.2 \mathrm{~T}$ magnetic field exhibits a typical textured microstructure. The picture has been taken on a fractured sample for which the observation plane contains the $c$-axis. Large platelets are compactly stacked up along the magnetic field direction.

Electrical resistivity versus temperature measurements were made using a standard four-probe technique with a

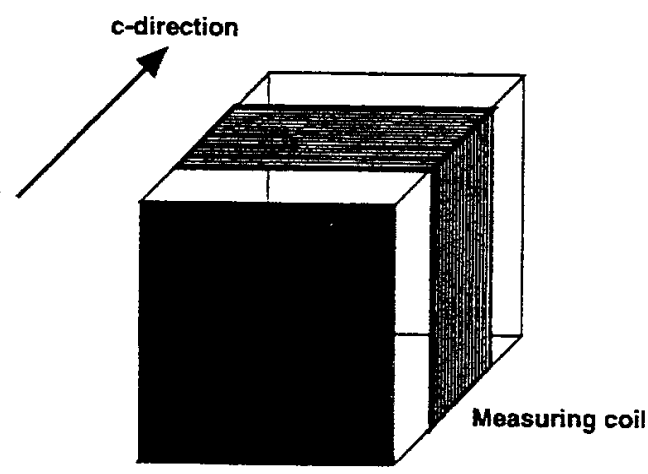

FIG. 4. Technical process used for the ac masnetic susceptibility measurements. 


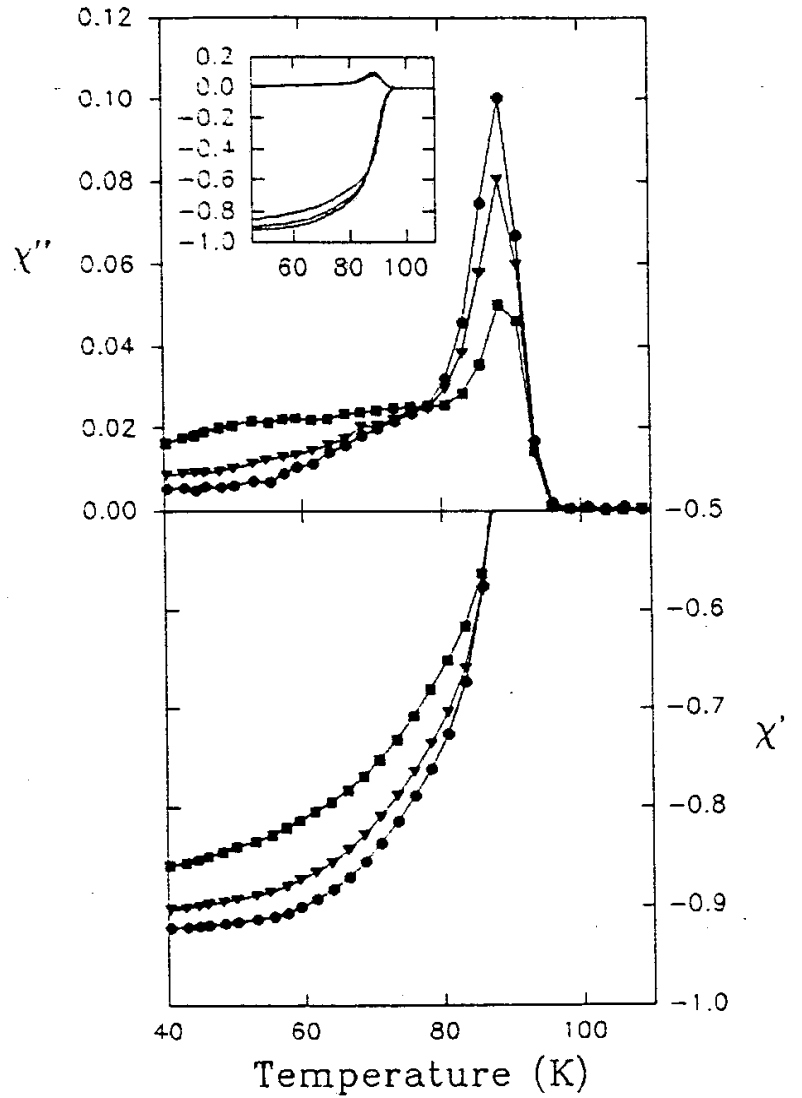

FIG. 5. ac susceptibility vs temperature of $\mathrm{Bi}_{2} \mathrm{Sr}_{2} \mathrm{Ca}_{0.8} \mathrm{Dy}_{0.2} \mathrm{Cu}_{2} \mathrm{O}_{3-y}$ sample textured in $1.2 \mathrm{~T}$ for three different orientations of the ac magnetic field- $\alpha$ is the angle between the $c$-axis and the direction of the field. $\alpha=0^{\circ}$. $\alpha=30^{\circ}$, and $\nabla \alpha=60^{\circ}$. The onset gives a general view of the ac magnetic suscepribility behavior as a function of $T$.

measuring current of $5 \mathrm{~mA}$ reversed several times in order to eliminate Peltier effects. ${ }^{17}$ Electrical resistivity versus temperature curves are shown in Fig. 3 for the cases in which the current is applied parallel ( $\mathbf{\square}$ ) or perpendicular $(\boldsymbol{)})$ to the magnetic field direction. The anisotropy of the resistivity curves confirms the texture. The resistivity above $T_{c}$ is much higher in the $c$ direction than in the ab plane, but is still of metallic type. This observation is consistent with the fact that the superconducting current flows in the copper oxide planes. The derivative curves of the electrical resistivity ( $\square$ and $O$ ) exhibit a $T_{c}$ of about $87 \mathrm{~K}$, characteristic of good $2212 \mathrm{ma}-$ terials.

ac magnetic susceptibility measurements have been made on a $\mathrm{Bi}_{2} \mathrm{Sr}_{2} \mathrm{Ca}_{0.8} \mathrm{Dy}_{0.2} \mathrm{Cu}_{2} \mathrm{O}_{8-y}$ sample prepared at $950^{\circ} \mathrm{C}$ under $1.2 \mathrm{~T}$ magnetic field. The sample was approximately a cube, with side length $6 \mathrm{~mm}$. Figure 4 shows the technical process used for the measurements. The measuring coil is turned perpendicularly to the $c$-axis of the sample. Figure 3(b) shows the real part $\left(\chi^{\prime}\right)$ and the imaginary part $\left(\chi^{\prime \prime}\right)$ of the ac susceptibility (corrected for demagnetizing factor) as a function of temperature. An ac field amplitude $h_{\mathrm{ac}}$ of $1 \mathrm{G}$ with a fixed frequency of $1053 \mathrm{~Hz}$ is used. By comparison with resistivity measurements [Fig. 3(a)], the onset of ac susceptibility corresponds to the initial decrease in electrical resistivity upon cooling. This is generally observed for highquality strongly coupled sintered superconductors. The real part of the ac susceptibility does not extrapolate exactly to -1 , indicating an imperfect diamagnetic shielding, probably due to the presence of a small percentage of nonsuperconducting impurity phases at the surface of the superconducting grains. In order to probe the texture of the sample, the ac magnetic susceptibility dependence on ac magnetic field angle is studied. The results are reported in Fig. 5(a) for $\alpha=30^{\circ}$ and $\alpha=60^{\circ}$. When the ac magnetic field is parallel to the $c$-axis of the sample $\left(\alpha=0^{\circ}\right)$, the supercurrents provide the maximum screening effect of the external magnetic field. This is not the case when $\alpha$ increases from $30^{\circ}$ to $60^{\circ}$, as shown in Fig. 5, resulting in a reduction of the diamagnetic shielding. As a consequence, the shielding currents have to flow within the sample leading to an increase of the dielectric losses as confirmed in the imaginary part $\left(\chi^{\prime \prime}\right)$ of the ac magnetic susceptibility at low temperature $\left(T<T_{c}\right)$ [Fig. 5(b)].

In summary, we propose in this article an easy way to texture partially substituted $\mathrm{Bi}_{2} \mathrm{Sr}_{2} \mathrm{CaCu}_{2} \mathrm{O}_{8-y} 2212$ material by melting under a $1.2 \mathrm{~T}$ magnetic field. The best thermal cycle has been given. Grain alignment was shown to be effective by $\mathrm{x}$-ray diffractometry, SEM, electrical transport measurements, and ac magnetic susceptibility.

The authors are grateful to Professor H. W. Vanderschueren for allowing them to use the facilities of the MIEL laboratory. S.S. is particularly grateful to the F.N.R.S. for financial aid and for the acquisition of the Siemens D5000 diffractometer. This work is part of the SUPRANAT SU/02/13 Superconductivity National Impulse Program of the Belgium Federal Services for Scientific Technical and Cultural Affairs (SSTC).

'P. de Rango. M. R. Lees, P. Lejay, A. Sulpice. R. Tournier, M. Ingoid. P. Germi. and M. Pernet, Nature 349, 770 (1991).

${ }^{2}$ R. Cloots, A. Rulmont. C. Hannay. P. A. Godelaine, H. W. Vanderschueren. P. Régnier, and M. Ausloos, Appl. Phys. Lett. 61, 2718 (1992).

${ }^{3}$ M. J. Cima, X. P. Jiang, H. M. Chow, J. S. Haggerty, M. C. Flemings, H.

D. Brady. R. A. Laudise, and D. W. Johnson, J. Mater. Res. 5, 1834 (1990).

${ }^{4}$ L. Dimesso, R. Masini, M. L. Cavinato, D. Fiorani, A. M. Testa, and C. Aurisicchio. Physica C 203, 403 (1992).

${ }^{5}$ S. Jin. R. B. van Dover, T. H. Tiefel, J. E. Graebner, and N. D. Spencer. Appl. Phys. Lett. 58. 868 (1991).

${ }^{6}$ N. McN Alford. T. W. Button, and J. D. Birchail, Supercond. Sci. Technol. 3. 1 (1990).

${ }^{7}$ A. Oota, M. Funakura, J. Iwaya, H. Matsui, and K. Mitsuyama. Physica C 212. 23 (1993).

${ }^{8}$ S. R. Arrasmith. M. J. Kramer, B. D. Merkle, T. G. Holesinger, and R. W. Mc Callum. J. Mater. Res. 8, 1247 (1993).

${ }^{9}$ Xiaoming Yang and T. K. Chaki, Supercond. Sci. Technol. 6, 269 (1993).

${ }^{10}$ J. G. Noudem. J. Beille, A. Draperi, A. Sulpice, and R. Tournier, Supercon. Sci. Technol. 6, 795 (1993).

${ }^{11}$ R. Cloots, A. Rulmont, H. Bougrine, and M. Ausloos-EUCAS'95, European Conference on Applied Superconductivity-3-6 July 1995Edinburgh-Scotland.

${ }^{12}$ F. Chen, R. S. Markiewicz, and B. C. Giessen, in Superconductivity and Applications, edited by Hoi S. Kwok, Y1-Han Kao, and David T. Shaw (Plenum. New York, 1989).

${ }^{13}$ S. Stassen. R. Cloots, Ph. Vanderbemden, P. A. Godelaine, H. Bougrine, A. Ruimont, and M. Ausloos, J. Mater. Res. (accepted for publication).

${ }^{14}$ E. Laxmi Narsaiah, U. V. Subba Rao, O. Peña, and C. Perrin, Solid State Commun. 83. 689 (1992).

${ }^{15}$ S. Stassen. R. Cloots, F. Gillet. A. Rulmont, and M. Ausloos, J. Mater. Res. 10, 1878 (1995).

${ }^{16} \mathrm{~S}$. Stassen, A. Rulmont, T. Krekels, M. Ausloos, and R. Cloots, J. Appl. Cryst. (to be published).

${ }^{17} \mathrm{Ch}$. Laurent, unpublished Ph.D. thesis, University of Liège, Belgium, 1988 (unpublished). 